\title{
THE SURVIVAL OF TRADITIONAL MEDICINE IN LAY MEDICAL VIEWS: AN EMPIRICAL APPROACH TO THE HISTORY OF,MEDICINE
}

\author{
by \\ VICKY RIPPERE*
}

IN A paper published over twenty years ago, Bruno Gebhard ${ }^{\mathbf{1}}$ drew attention to a question that still remains relatively neglected by historians of medicine. This question concerned the survival of traditional medical wisdom in the beliefs about health and illness in daily life that are held by contemporary lay people. Lay medicine, he noted, contained "elements ... which are condensations of century-old traditions and which have survived the test of time" (p. 46). But despite the increasing interest in the history of medicine, little seems to be known about lay medical beliefs and less still of the way in which they may preserve orthodox medical wisdom. The logic of the question would seem to require that we define certain "historical" beliefs and that we establish their continuing presence in contemporary popular thoughts.

The present paper describes an empirical method which has been used to collect data bearing on this fascinating topic. While the particular subject matter which has been studied with the method - historical views on factors affecting people's ability to develop depression - is relatively circumscribed and the people studied to date restricted to English-speaking adults resident in Great Britain, the method itself could readily be adapted to other bodies of subject matter and other groups of people.

The research in question belongs to an ongoing series of studies of what I have called antidepressive behaviour, ${ }^{2,3}$ e.g., those deliberately undertaken, rule-following activities, such as seeing a friend, going for a walk, trying to work out why they are feeling depressed and doing something about that, etc., by which people manage their feelings of depression in everyday life, and of the network of associated, sociallyshared beliefs which constitute what Berger and Luckmann ${ }^{4}$ have termed social stock of knowledge, on the subject of depression and its self-management. In the course of developing objective, empirical methods for studying these familiar, everyday

\footnotetext{
*Vicky Rippere, Ph.D., M.Phil., Department of Psychology (Clinical), Institute of Psychiatry, De Crespigny Park, Denmark Hill, London SE5 8AF.

1 Bruno Gebhard, 'Historical relationships between scientific and lay medicine for present-day patient education', Bull. Hist. Med., 1958, 32; 46-53.

2 Vicky Rippere, 'Antidepressive behaviour', unpublished.M.Phil. dissertation, University of London, 1974.

${ }^{3}$ Vicky Rippere, 'Antidepressive behaviour - a preliminary report', Behav. Res. \& Therapy, 1976, 14: 289-299.

4 Peter L. Berger and Thomas Luckmann, The social construction of reality, London, Allen Lane, 1967, pp. 56-61.
} 
phenomena, I found that people's knowledge of the socially-shared "rules to follow" could be tapped directly by asking them to answer the simple question, "What's the thing to do when you're feeling depressed?" 2.5 and submitting their responses to content analysis and frequency counts.

The majority of responses produced by a group of fifty English-speaking people aged nine to sixty-eight in answer to the question were consensual (e.g. produced by more than one person independently). Up to 36 per cent of the group concurred in mentioning the most frequently named item ("see a friend"). Besides the first-order unitary items that were produced, some 15 per cent of all responses were other rulelike remarks qualifying first-order rules. These "qualifiers" took the form of comments to the effect that " "the' thing to do" depended upon such factors as who and how depressed the person was and the opportunities available to him at the time.

The next stage of the research was to tap the higher-order beliefs associated with the rules and meta-rules uncovered in the first stage. To this end a paradigm was developed that is both simple and versatile. Its only practical limitations are that studies need to be conducted within a natural group setting, such as a class meeting or a public or course lecture and that the people comprising the group have to be numerate to the extent of possessing a working concept of percentage. Subjects are given to fill in a brief questionnaire on some aspect of depression, such as the frequency, intensity, and duration of feelings of depression which they experience and which they attribute to the hypothetical average person, ${ }^{6,7}$ or how helpful they find each of a list of typical antidepressive activities. ${ }^{8}$ Then, as a second task, they are asked to predict the group's results, either by estimating the proportion of the group that will choose each point on the qualitative scales on which they have been asked to indicate their answers or by indicating the average quantitative scale rating that they think the group will assign to the items. The means of their estimates are then compared to the figures actually observed. The degree of agreement between observation and estimate can be assessed either by visual inspection of graphs of the distribution of data points, as in the first case, or by statistics (e.g. Spearman Rank Order Correlation Coefficients), as in the second case. In the studies conducted to date, the student and professional groups who have attempted to predict their own responses to the novel questionnaires have been extremely accurate in their estimates, on average.

The prediction paradigm has since been extended to the study of social consensus about discursive propositions, and it is here that its particular relevance to the question of lay medical beliefs is found.

In the first study in this series, ${ }^{9}$ the group was given a questionnaire containing ten matched pairs of propositions, representing contemporary lay and scientific views on the nature and treatment of depression. They were asked to endorse one member of

\footnotetext{
'Vicky Rippere, "“What's the thing to do when you're feeling depressed?" - a pilot study', Behav. Res. \& Therapy, 1977, 15; 185-191.

6 Vicky Rippere, 'Some cognitive dimensions of antidepressive behaviour', ibid., 1977, 15: 57-63.

'Vicky Rippere, 'Frequency, intensity and duration of other people's self-reported depression', ibid., 1980, 18: 259-264.

- Vicky Rippere, 'Scaling the helpfulness of antidepressive activities', ibid., 1979, 17: 439-449.

- Vicky Rippere, 'Predicting consensus about propositions concerning depression and antidepressive behaviour: another cognitive dimension of commonsense knowledge', ibid., 1980, 18: 79-86.
} 
each pair and to estimate the percentage of the group that they thought would endorse them. The mean estimated percentages were compared to those actually observed and a high degree of agreement was found. On the whole, the group members appeared to possess accurate quantitative notions of the extent of agreement about the various propositions that existed amongst their peers. The content of their endorsements was also of interest. Here it was found that people tended to agree more about matters that could be verified by personal experience than with views that experts still debated.

The second study in the series ${ }^{10}$ represented an extension of the enquiry to the realm of historically-derived propositions. The same basic format was used, but the propositions represented beliefs that belonged to the canon of ancient medical wisdom as it was popularized in English from the early sixteenth century. ${ }^{11}$ The propositions were formulated as generalizations in modern English (e.g. "Improper diet can contribute to making people depressed and a proper diet can help prevent depression"), and were paired with propositions representing the contrary view (e.g. "A person's diet is probably unrelated to whether or not he gets depressed"). The ten propositions covered the areas of Galen's six non-naturals (climate, sleep, activity, diet, excretion, and regulation of emotion) and the questionnaire was administered to three separate groups of people in order to assess the consistency of results. As the results appeared to be generally consistent across groups, they were combined so that the final findings represent the responses of sixty-four people. As in the previous study, subjects were also asked to estimate proportions of the group endorsing each statement, but as these findings are not particularly of interest in the present context, they will not be reported again here. The ten pairs of historical propositions and their antitheses are shown in Table 1 in order of degree of consensus. The numbers preceding the statements refer to their position in the questionnaire. Those marked with an asterisk $\left(^{*}\right)$ represent beliefs consistent with the historical canon of ideas.

The table shows that a clear majority of people in the present group of young English-speaking adults endorsed eight of the ten "historical" propositions, endorsed the antithesis of a ninth, and disagreed among themselves in equal numbers about the tenth. The finding suggests that a substantial majority of the ten historical beliefs studied are still represented in the medical beliefs of modern lay English speakers. ${ }^{12}$

The results do not explain either the means by which the surviving views have preserved their vitality in the face of centuries of social and medical change or the reasons why the others have fallen out of favour. Such questions would need to be answered by argument from more qualitative, discursive sorts of evidence. An empirical method such as the one demonstrated here will supplement rather than supplant more traditional methods for studying the history of medicine, but it may nonetheless contribute in a unique way to answering certain important types of question.

\footnotetext{
10 Vicky Rippere, 'Some historical dimensions of commonsense knowledge about depression and antidepressive behaviour', ibid., 1980, 18: 373-385.

${ }^{11}$ For an extended discussion of this canon of advice, see Vicky Rippere, 'Behavioural treatment of depression in historical perspective', in S. Rachman (editor) Contributions to medical psychology, Oxford, Pergamon Press, 1980, vol. 2, pp. 31-54.

12 For a parallel investigation into the survival of historical beliefs in modern medicine, see C. G. Helman, " "Feed a cold, starve a fever" - folk models of infection in an English suburban community, and their relation to medical treatment', Medicine and Society, 1978, 2: 107-137.
} 
TABLE 1 - OBSERVED PERCENTAGE OF PEOPLE $(n=64)$ ENDORSING STATEMENTS

\begin{tabular}{|c|c|}
\hline & Statement \\
\hline * $1 \mathrm{a}$ & $\begin{array}{l}\text { Some types of people are more likely than others to } \\
\text { become depressed. }\end{array}$ \\
\hline b & $\begin{array}{l}\text { The chances of becoming depressed are pretty much } \\
\text { the same for everyone. }\end{array}$ \\
\hline $22 a$ & $\begin{array}{l}\text { The way people live is not an important factor in whether } \\
\text { or not they get depressed. }\end{array}$ \\
\hline * b & $\begin{array}{l}\text { The way people live can be an important factor in } \\
\text { whether or not they get depressed. }\end{array}$ \\
\hline $5 a$ & $\begin{array}{l}\text { A person's diet is probably unrelated to whether or not } \\
\text { he gets depressed. }\end{array}$ \\
\hline${ }^{*} \mathrm{~b}$ & $\begin{array}{l}\text { An improper diet can help bring on a depression and a } \\
\text { proper diet can help protect people from it. }\end{array}$ \\
\hline *8a & $\begin{array}{l}\text { Keeping one's bowels regular is important in preventing } \\
\text { depression. }\end{array}$ \\
\hline b & $\begin{array}{l}\text { Keeping one's bowels regular has little to do with } \\
\text { preventing depression. }\end{array}$ \\
\hline *3a & $\begin{array}{l}\text { The weather and climate can affect people's liability to } \\
\text { depression. }\end{array}$ \\
\hline b & $\begin{array}{l}\text { People's liability to depression is generally unaffected by } \\
\text { weather and climate. }\end{array}$ \\
\hline $9 a$ & $\begin{array}{l}\text { A philosophical outlook isn't really much use when } \\
\text { things go wrong in one's life. }\end{array}$ \\
\hline * b & $\begin{array}{l}\text { A philosophical outlook may help a person when things } \\
\text { go wrong in his life. }\end{array}$ \\
\hline $4 a$ & $\begin{array}{l}\text { The amount of sleep a person gets is probably unrelated } \\
\text { to whether or not he gets depressed. }\end{array}$ \\
\hline${ }^{*} \mathrm{~b}$ & $\begin{array}{l}\text { Loss of sleep can help bring on a depression and obtaining } \\
\text { adequate sleep can help prevent it. }\end{array}$ \\
\hline${ }^{*} 7 a$ & $\begin{array}{l}\text { An active person is less likely to get depressed than one } \\
\text { who is idle. }\end{array}$ \\
\hline b & $\begin{array}{l}\text { A jerson's amount of activity is unlikely to contribute } \\
\text { much to whether or not he gets depressed. }\end{array}$ \\
\hline $6 a$ & $\begin{array}{l}\text { The amount of exercise a person gets is probably un- } \\
\text { related to whether or not he gets depressed. }\end{array}$ \\
\hline * b & $\begin{array}{l}\text { Insufficient exercise can help bring on a depression and } \\
\text { sufficient exercise can help prevent it. }\end{array}$ \\
\hline${ }^{*} 10 \mathrm{a}$ & $\begin{array}{l}\text { Keeping a check on one's emotions may be helpful in } \\
\text { preventing depression. }\end{array}$ \\
\hline & $\begin{array}{l}\text { Keeping a check on one's emotions is not much use in } \\
\text { preventing depression. }\end{array}$ \\
\hline
\end{tabular}

Observed \% Consensus with historical view

89.06

87.50

76.56

50.00

50.00

\section{SUMMARY}

Little is known about the way in which contemporary lay medical beliefs may preserve orthodox medical wisdom of the past. To examine this question it is necessary to establish the continuing presence of former orthodox views in current socially-shared popular medical beliefs. This paper describes a method evolved for this purpose. A group of people fill in a questionnaire in which they are asked to endorse one member of each of several pairs of statements representing opposing views on a topic. The degree of consensus in their endorsements provides a crude index of the relative strength of the endorsed beliefs amongst contemporary people. A study is reported in which the propositions in question were derived from the neoclassical canon of medical doctrine on the nature of depression and its prevention. 